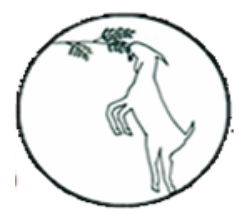

Agropecuária Científica no Semiárido

Centro de Saúde e Tecnologia Rural

http://revistas.ufcg.edu.br/acsa/index.php/ACSA/index

ISSN: 1808-6845

http://dx.doi.org/10.30969/acsa.v16i4.1306

\title{
Influência do Uso e Ocupação da Terra no Risco de Ocorrência de Incêndios Florestais
}

\author{
Leonardo Duarte Biazatti ${ }^{1}$, Nilton Cesar Fiedler ${ }^{1 *}$, Antonio Henrique Cordeiro Ramalho ${ }^{1}$, Daniel Pena \\ Pereira $^{1}$, Alexandre Rosa dos Santos ${ }^{1}$, Giselle Lemos Moreira ${ }^{2}$
}

\begin{abstract}
RESUMO: A presente pesquisa objetivou apurar a influência do uso e ocupação da terra (UOT) no risco de incêndios florestais para o Monumento Natural da Serra da Ferrugem e sua zona de amortecimento no Município de Conceição do Mato Dentro, Minas Gerais. Para tal, realizou-se a fotointerpretação de imagens aéreas elaborando-se o mapa de caracterização do UOT, sobre o qual aplicou-se a função de pertinência Fuzzy Gaussian para determinar sua influência no risco de incêndios. Compilou-se a série histórica de 10 anos de focos de calor identificados na área para verificar a assertividade do modelo. Como resultado foram identificadas 9 classes, sendo elas: Afloramento Rochoso; Antropização; Floresta Plantada; Lago; Mata Nativa; Pastagem; Cerrado; Solo Exposto e Área Urbana. A tipologia de Mata Nativa, enquadrada na classe de risco moderado, é a de maior representatividade. Desta forma, foi possível concluir que, para o uso e ocupação da terra, a área possui risco moderado de ocorrência de incêndios e que o modelo foi eficaz, pois nenhum dos focos de calor ocorreu sobre classes de risco muito baixo e baixo.
\end{abstract}

Palavras-chave: Proteção florestal; Logica Fuzzy; Sistemas de Informações Geográficas; Áreas Protegidas.

\section{Influence of Land Use and Occupation on the Risk of Forest Fires}

\begin{abstract}
This research aimed to investigate the influence of land use and occupation (LUO) on the risk of forest fires for the Serra da Ferrugem Natural Monument and its buffer zone in the Municipality of Conceição do Mato Dentro, Minas Gerais. For this purpose, the photointerpretation of aerial images was carried out, drawing up the LUO characterization map, on which the Fuzzy Gaussian membership function was applied to determine its influence on fire risk. A 10-year historical series of hot spots identified in the area was compiled to verify the model's assertiveness. As a result, 9 classes were identified, namely: Rocky Outcrop; Anthropization; Planted Forest; Lake; Native Forest; Pasture; Savannah; Exposed Soil; Urban area. The Native Forest typology, classified in the moderate risk class, is the most representative. Thus, it was possible to conclude that for the use and occupation of land the area has a moderate risk of fire occurrence and that the model was effective because none of the hot spots occurred under very low and low risk classes.
\end{abstract}

Keywords: Forest protection; Fuzzy Logic; Geographic Information Systems; Protected Areas.

\section{INTRODUÇÃO}

Incêndio florestal é definido como todo fogo sem controle que atinge áreas compostas por cobertura vegetal, podendo ser resultante de ações antrópicas ou naturais, que prejudica espécies animais, vegetais e vidas humanas. Estes episódios acarretam vários efeitos negativos ao meio ambiente, entre os quais destacam-se: aumento da poluição do ar, destruição de benfeitorias, diminuição da fertilidade, acréscimo das taxas de erosão do solo e escoamento superficial, acarretando o assoreamento dos corpos hídricos (FIEDLER et al., 2020a).

De acordo com Telbadi et al. (2013) e Koproski et al. (2011), os incêndios são as principais ameaças às unidades de Conservação (UCs). No Brasil, as maiores causas dos incêndios em áreas protegidas são vandalismo, atividades de recreação ou até mesmo negligência (FIEDLER et al., 2020b; SMA, 2021).
Todo incidente com fogo é complexo, diferente e, em muitos casos, difícil de se combater em função das diversas características das áreas de ocorrência. $\mathrm{O}$ estado de Minas Gerais possui em seu território domínios fitogeográficos da Mata Atlântica, do Cerrado e da Caatinga, ou seja, possui uma grande superfície com diferentes áreas de transição de biomas que possuem forte influência no equilíbrio da biodiversidade (VELOSO et al., 2012).

As informações acerca dos casos de incêndios florestais, principalmente em unidades de conservação, ainda são escassas, e isso gera duas possíveis situações: a criação de planos de combate e prevenção superfaturados ou investimentos abaixo do necessário colocando em risco a segurança dessas áreas protegidas (RODRÍGUEZ et al., 2013). 
Assim, diante do crescente aumento da frequência dos casos de incêndios florestais, da constatação de seu poder destrutível e da complexidade de previsão dos incidentes, a busca por ferramentas que auxiliem na prevenção e no combate dos sinistros tornou-se indispensável.

Dentro desse contexto, surgem novas metodologias como o zoneamento de risco de incêndios florestais associado a lógica $F u z z y$ que vem se mostrando bastante eficiente no auxílio ao planejamento de proteção das Unidades de Conservação (EUGENIO et al., 2016).

Sabendo-se que o risco de incêndios está relacionado com as condições ambientais e características da área, que se manifestam gerando o potencial de ocorrência de focos de calor, e dado que grande parte dos incêndios possui como causa alguma atividade antrópica, a realização de uma análise criteriosa da biodiversidade do local por meio do uso e ocupação da terra (UOT), correlacionando-o com a capacidade de criação de fontes de ignição, pode ser uma ferramenta crucial para entender o risco de ocorrência de incêndios em diferentes regiões (BATISTA, 2000; MEDEIROS, 2002; MEDEIROS \& FIEDLER, 2004; FIEDLER et al., 2006).
Desta forma, a presente pesquisa foi elaborada a partir da hipótese de que a aplicação da modelagem Fuzzy pode indicar às áreas mais susceptíveis à ocorrência de incêndios, objetivando apurar a influência do uso e ocupação da terra no risco de incêndios florestais para o Monumento Natural da Serra da Ferrugem e sua zona de amortecimento no Município de Conceição do Mato Dentro, Minas Gerais.

\section{MATERIAL E MÉTODOS}

A área de estudo compreende o Monumento Natural (MONA) da Serra da Ferrugem e sua Zona de Amortecimento localizada no município de Conceição do Mato Dentro, no Estado de Minas Gerais situada sob as coordenadas $43^{\circ} 26^{\prime} 0^{\prime \prime}$ e $43^{\circ} 22^{\prime} 0^{\prime \prime}$ Latitude Oeste e $18^{\circ} 56^{\prime} 0^{\prime \prime}$ e $19^{\circ} 4^{\prime} 0^{\prime \prime}$ Longitude Sul.

O clima, de acordo com a classificação climática de Köppen, é do tipo Cwa (quente e temperado), com temperatura média anual de $20,9^{\circ} \mathrm{C}$ e precipitação média anual de $1.682 \mathrm{~mm}$. A área possui aproximadamente 11.193,07 ha, sendo 867,29 ha pertencentes à MONA da Serra da Ferrugem. O relevo varia entre $430 \mathrm{~m}$ e $1460 \mathrm{~m}$ de altitude (OLIVEIRA, 2019), como ilustra a Figura 1.

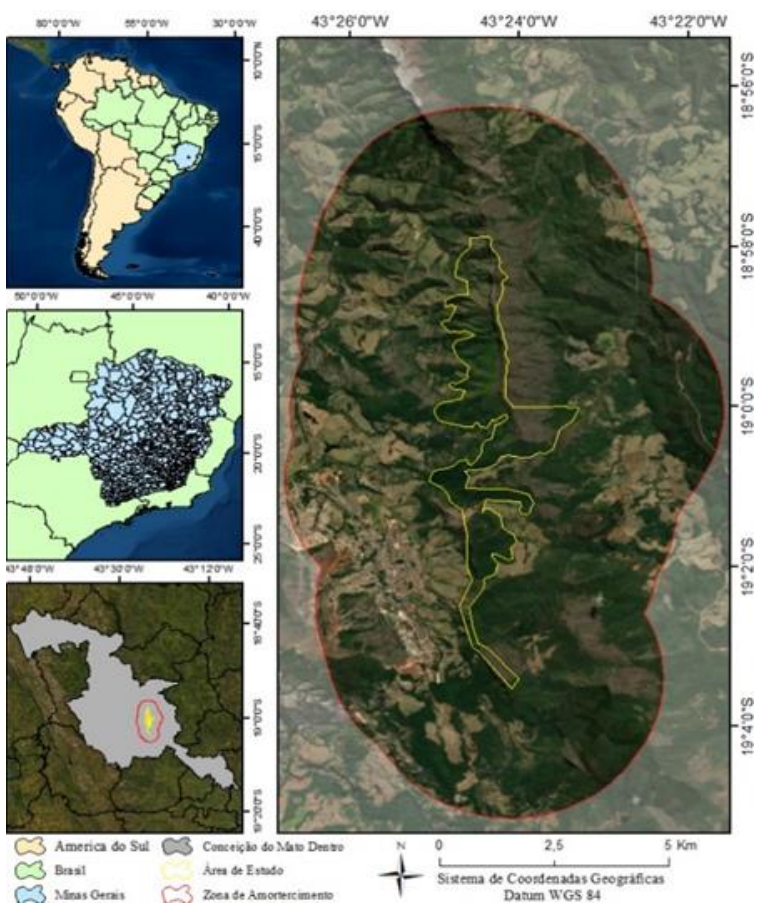

Figura 1 - Mapa de localização da área de estudo.

Fonte: $\mathrm{O}$ autor.

Para a elaboração do mapa de influência do uso e ocupação da terra (UOT) no risco de incêndios florestais, foram utilizadas as seguintes etapas metodológicas adaptadas de Juvanhol (2014): foto interpretação da imagem aérea do uso e ocupação da terra; edição da tabela de atributos; compilação da série histórica de focos de calor; combinação dos arquivos pontuais dos focos de calor; aplicação da função de pertinência; aplicação dos focos de calor e reclassificação das classes de influência.

As imagens aéreas da área foram obtidas através da plataforma Geobases e sobre estas ortofotos aplicou-se técnicas de fotointerpretação com o auxílio do software Arcgis, versão 10.3, para identificar, 
delimitar e, posteriormente, caracterizar as classes de uso e ocupação da terra existentes na área de estudo.

Em caso de dúvidas na visualização, recorreu-se aos arquivos disponibilizados pela plataforma Google Earth Engine, mais precisamente do projeto MapBiomas, referente ao ano de 2019, coleção 5.0, com resolução espacial de $30 \mathrm{~m}$ e resolução temporal anual (MAPBIOMAS, 2021).

Após a interpretação visual das imagens, procedeu-se a atualização da tabela de atributos com as classes identificadas, sendo elas: Afloramento Rochoso; Antropização; Floresta Plantada; Lago; Mata Nativa; Pastagem; Cerrado; Solo Exposto e Área Urbana. Com a finalização destas etapas, elaborou-se o mapa de caracterização do uso e ocupação da terra.

Com o intuito de validar o potencial de ignição de cada classe do UOT, compilou-se a série histórica de 10 anos de registros de focos de calor na área. Os arquivos foram captados através da plataforma BDQueimadas do Instituto Nacional de Pesquisas Espaciais (INPE), mais precisamente as produções do satélite de referência AQUA tarde (INPE, 2021).
Os focos de calor não correspondem necessariamente a incêndios florestais; porém, seu aparecimento comprova uma maior suscetibilidade ou probabilidade de ocorrência de fogo.

Após obter todos os arquivos pontuais referentes aos focos de calor, foi necessário combiná-los dentro do software Arcgis, versão 10.3, para que se tornassem uma única imagem.

Para definir a influência de cada classe de uso e ocupação da terra identificada, aplicou-se a lógica Fuzzy que traduz um valor qualitativo em numérico, inserindo-o em um conjunto de valores do intervalo entre 0 e 1 (GAGLIONE et al., 2019; NADERPOUR et al., 2019; OLIVEIRA et al., 2013; RAMALHO et al., 2021).

Definiu-se que a função de pertinência a ser utilizada seria a Fuzzy Gaussian, conforme executado por Juvanhol (2014). Esta função cria uma distribuição normal do conjunto, reclassificando ao redor de um ponto central o qual recebe o maior valor de risco. $\mathrm{O}$ valor de propagação da curva foi de $0,1 \mathrm{e}$ a classe definida como ponto central foi a de "pastagem" (Tabela 1).

Tabela 1. Reclassificação do UOT de acordo com a influência sobre os riscos de incêndios florestais.

\begin{tabular}{ccc}
\hline Classe de UOT & Valor reclassificado & ROIF \\
\hline Lago & 1 & Muito baixo \\
Afloramento Rochoso & 2 & Baixo \\
Mata Nativa & 3 & Moderado \\
Floresta Plantada & 4 & Alto \\
Pastagem & $5^{*}$ & Muito alto \\
Cerrado & 6 & Alto \\
Antropização & 7 & Moderado \\
Área Urbana & 8 & Baixo \\
Solo Exposto & 9 & Muito baixo \\
\hline
\end{tabular}

Fonte: Adaptado de Camelo, Sanches e Nakagomi (2020); Marchesan et al. (2020); Ribeiro et al. (2008) e Soares Neto et al. (2016).

Finalizada a aplicação da lógica Fuzzy, gerou-se o mapa da influência do uso e ocupação da terra no risco de ocorrência de incêndios e, sobre esse arquivo matricial, aplicou-se os focos de calor combinados para verificar a assertividade do modelo. Em sequência, prosseguiu-se com a reclassificação das classes de influência, aplicando-se a reclassificação natural de Jenks para se obter 5 classes de risco: Muito baixo, que é a mais próxima de 0 no conjunto
Fuzzy; Baixo; Moderado; Alto e Muito Alto, sendo essa última a que mais se aproxima de 1 no conjunto Fuzzy (RAMALHO et al., 2021).

A Figura 2 representa o fluxograma metodológico executado para elaborar o mapeamento das classes de uso e ocupação da terra bem como verificar sua influência no risco de ocorrência de incêndios florestais. 


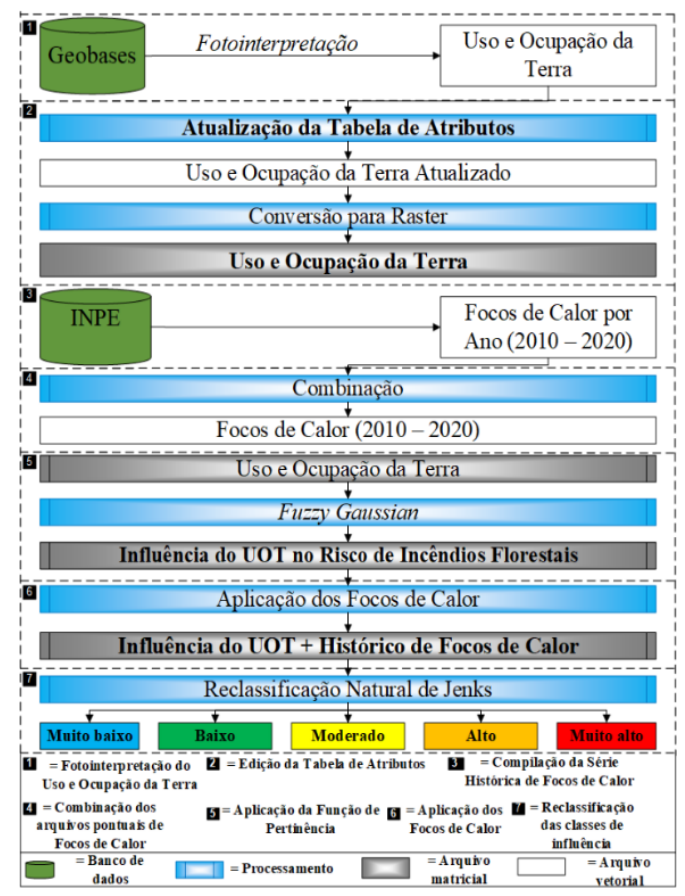

Figura 2 - Fluxograma Metodológico

Fonte: O Autor.

\section{RESULTADOS E DISCUSSÕES}

O mapa de caracterização do uso e ocupação da terra para o Monumento Natural da Serra da Ferrugem e sua zona de amortecimento permitiu compreender a organização do espaço e identificar as atividades realizadas na área de estudo.

A classe encontrada que possui a maior representatividade foi a Mata Nativa, com 6.120,01 ha $(54,68 \%$ do território), seguida da classe de Cerrado, com $2.137,96$ ha $(19,10 \%$ da área). A terceira classe em representatividade foi a de Pastagem, com 1.719,72 ha (16\% da área).
A classe de menor relevância foi a de Afloramento Rochoso correspondendo a apenas 4,03 ha $(0,04 \%$ do território), seguida por Lago, com 14,13 ha $(0,13 \%)$ e Antropização 43,86 ha (0,39\%). A área urbana possui 318,35 ha correspondendo a $2,84 \%$ da área. A superfície ocupada por Florestas Plantadas correspondeu a 647,15 ha $(5,18 \%$ da área $)$. A área de solo exposto foi de 115,81 ha $(1,03 \%)$. A Figura 3 ilustra estes resultados e demonstra sua distribuição sobre a área.

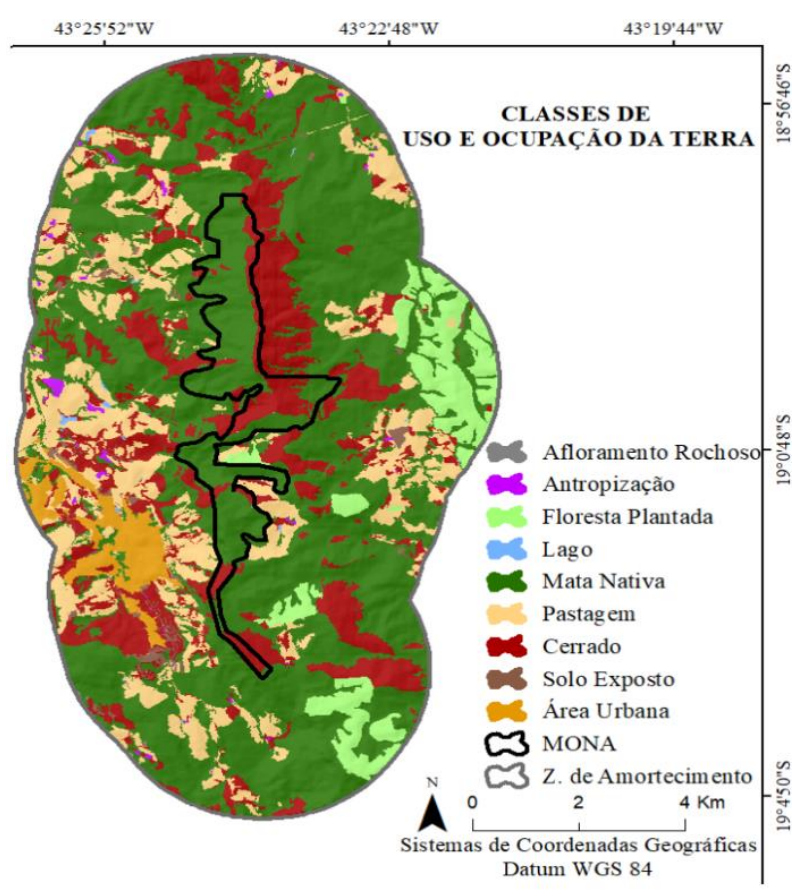

Figura 3. Caracterização das classes de uso e ocupação da terra Fonte: $\mathrm{O}$ autor. 
A Figura 4 apresenta a influência das classes de uso e ocupação da terra no risco de ocorrência de incêndios e os focos de calor identificados.

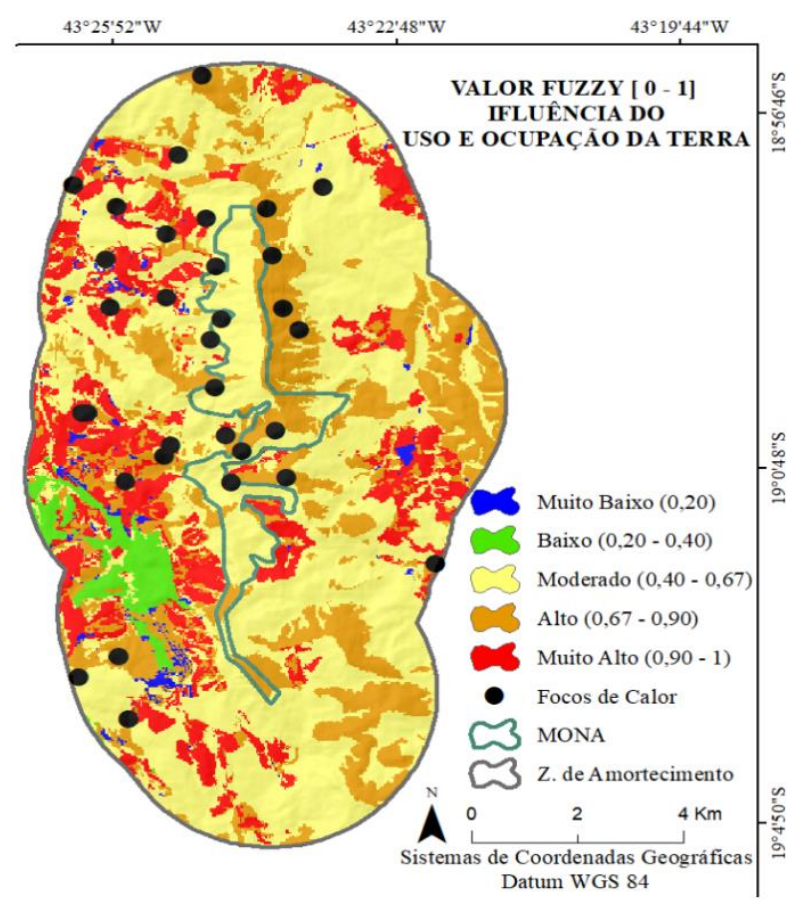

Figura 4. Influência do uso e ocupação da terra sobre o risco de ocorrência de incêndios florestais. Fonte: $\mathrm{O}$ autor.

Ao se observar o mapa da Figura 4 fica nítido que o uso e ocupação da terra influencia, colocando o risco de ocorrência de incêndios como moderado, pois esta é a classe com maior representatividade. As fisionomias que se enquadram no risco moderado são as de Mata Nativa e Antropização, fazendo com que a proporção desta classe seja de 55,07\% do território.

Sabe-se que regiões com fragmentos florestais nativos possuem alta retenção de umidade por conta de seus dosséis geralmente fechados e a grande concentração de raízes no solo, o que pode diminuir seu potencial de ignição. Todavia, sob condições de seca ou altas temperaturas, tais áreas podem se tornar vulneráveis ao fogo pela quantidade de material vegetal produzido dentro das florestas (ARAÚJO et al, 2013). Isso ainda pode ser potencializado pela proximidade a áreas com antropização, tendo em vista que a presença de atividade humana sempre é um fator de elevação do risco de incêndios, o que justifica o enquadramento destas tipologias na classe de risco moderado.

A classe de risco alto é a segunda em representatividade, pois compreende as classes de Cerrado e Floresta Plantada, totalizando 24,28\% da área. O risco alto é atribuído a Floresta Plantada pelo fato de que a espécie utilizada nestes plantios é o Eucalipto, árvore essa que produz muita matéria orgânica seca como folhas, galhos e cascas que possuem alta inflamabilidade, além de possuir copas ralas o que possibilita maior entrada de radiação solar quando comparada a florestas nativas.

Outro fator elevador do risco em florestas plantadas é a própria atividade de colheita, onde são utilizados maquinários que elevam o potencial de combustão dos materiais vegetais secos presentes no solo, considerando-se ainda a presença humana nessas atividades. Segundo Soares e Batista (2007), 99\% dos incêndios que ocorrem no Brasil são consequência de ações antrópicas.

O cerrado brasileiro possui, em sua maioria, uma vegetação rasteira e rala, com árvores espaçadas com galhos mais secos e retorcidos (RIBEIRO; WALTER, 2008).

A classe de risco muito alto corresponde a pastagem (16\% do território). Segundo Juvanhol (2014), existem registros de que em áreas de pastagens a temperatura aumenta $10^{\circ} \mathrm{C}$ acima das regiões de floresta, e a umidade decresce cerca de $35 \%$, por conta da constante exposição à radiação solar, aumentando muito a probabilidade de ocorrer a queima e proporcionando o ambiente ideal para a propagação do fogo.

As regiões correspondentes à classificação de risco baixo são respectivamente a área urbana e afloramento rochoso, sendo 2,88\% da área de estudo.

Apesar de possuir alta circulação humana, a área urbana foi classificada como risco baixo pelo distanciamento das áreas de floresta. Essa distância diminui sua influência visto que, de acordo com Melo 
(2018), áreas marginais a rodovias e cidades estão sujeitas a incêndios causados por veículos, cargas, fogueiras ou descarte de material inflamável por parte dos moradores e transeuntes, ou seja, quanto mais próximo das áreas de urbanização, maior o risco, e aumentando-se a distância, o risco diminui.

A classe de afloramento rochoso se enquadrou no risco baixo por possuir pouco volume de material combustível. O risco muito baixo envolve as áreas de lago e solo exposto, por serem locais inundados e sem vegetação, tornando-se barreiras naturais contra a propagação do fogo (JUVANHOL, 2014).

Observando a ocorrência de focos de calor, percebe-se que sua maioria (30 de 32) ocorreu sobre as classes de risco alto e muito alto, sendo que os anos com maior incidência foram 2019 (13 focos) no mês de setembro e 2014 (16 focos) no mês de outubro, coincidindo com as épocas de menor precipitação destes anos, segundo dados da plataforma WORLDCLIM (WORLDCLIM, 2021). Tais valores asseguram a influência do uso e ocupação da terra na suscetibilidade ao fogo principalmente em condições adversas de clima como períodos de estiagem. A maior densidade de focos nestas classes reforça que as atividades onde há maior presença humana como os plantios florestais expõem o território ao risco de queimadas, além de comprovar que vegetações mais secas e rasteiras, como o caso das classes de Cerrado e pastagem, possuem maior combustibilidade.

\section{CONCLUSÕES}

Considerando o uso e ocupação da terra, pode-se dizer que a área de estudo possui risco moderado por conta da grande representatividade da fitofisionomia de mata nativa. Porém, o modelo também mostrou a existência de áreas enquadradas nas classes de risco alto e muito alto as quais necessitam de maior vigilância, comprovando que a análise da influência do uso e ocupação da terra auxilia na predição e pode facilitar o planejamento estratégico, indicando as áreas mais susceptíveis aos incêndios.

A modelagem Fuzzy também se mostrou eficaz, pois todos os episódios de focos de calor registrados durante 10 anos ocorreram nas classes de risco moderado, alto e muito alto.

\section{REFERÊNCIAS}

ARAÚJO, R.; ANDREOLI, R. V.; CANDIDO, L. A. C.; KAYANO, M.; SOUZA, R. A influência do ENOS e Atlântico Equatorial na precipitação sobre a região norte e nordeste da América do Sul. Acta Amazonica, v. 43, n. 4, 2013.
BATISTA. A. C. Mapas de risco: uma alternativa para o planejamento de controle de incêndios florestais. Revista Floresta, v.30, 45-54, 2000.

CAMELO, A. P. S.; SANCHES, K.; NAKAGOMI, B. Zoneamento de incêndios florestais na Estação Ecológica Águas Emendadas, Distrito Federal (Brasil). Territorium, v. 27 , n. 2 , p. $67-79,2020$.

EUGENIO, F. C. et al. Applying GIS to develop a model for forest fire risk: A case study in Espírito Santo, Brazil. Journal of Environmental Management, v. 173, p. 6571, 2016.

FIEDLER N. C., MERLO A. M., MEDEIROS, M.B. Ocorrência de incêndios florestais no Parque Nacional da Chapada dos Veadeiros, Goiás. Ciência Florestal; 16(2): 153-161, 2006.

FIEDLER, N. C. et al. Firefighting combat with fire retardants at different concentrations. Floresta, v. 50, n. 1, p. 1107-1112, 2020a.

FIEDLER, N. C. et al. Causas dos incêndios florestais. In: FIEDLER, N. C.; SANT'ANNA, C. DE M.; RAMALHO, A. H. C. (Eds.). . Incêndios Florestais. 1. ed. Jerônimo Monteiro - ES: UFES, 2020b. p. 55-64.

GAGLIONE, S. et al. Fuzzy logic applied to GNSS. Measurement: Journal of the International Measurement Confederation, v. 136, p. 314-322, 2019.

INPE. Programa Queimadas - Banco de Dados de Queimadas. Disponível em: <http://queimadas.dgi.inpe.br/queimadas/bdqueimadas/\#> . Acesso em: 15 Jul. 2021.

JUVANHOL, R.S. Modelagem da vulnerabilidade à ocorrência e propagação de incêndios florestais. 2014. 77f.: Dissertação (Mestrado em Ciências Florestais) Universidade Federal do Espírito Santo, Espirito Santo.

KOPROSKI, L.; FERREIRA, M. P.; GOLDAMMER, J. G.; BATISTA, A. C. Modelo de zoneamento de risco de incêndios para unidades de conservação brasileiras: o caso do Parque Estadual do Cerrado (PR). Floresta, Curitiba, v. 41, n. 3, p. 551-562, 2011.

MAPBIOMAS. Coleções MapBiomas: Coleção 5 (1985 - 2019), Mata Atlântica. Disponível em: <https://mapbiomas.org/colecoes-mapbiomas-

1?cama_set_language=pt-BR>. Acesso em: 15 jul. 2021.

MARCHESAN, J. et al. Risco de incêndios na Estação Ecológica do Taim, Rio Grande do Sul. Nativa, v. 8, n. 1, p. $112,2020$.

MEDEIROS, M. B. Manejo de fogo em unidades de conservação do cerrado. Boletim do Herbário Ezechias Paulo Heringer; v.10, n.1, p.76-89, 2002. 
MEDEIROS, M. B.; FIEDLER, N. C. Incêndios florestais no Parque Nacional da Serra da Canastra: desafios para a conservação da biodiversidade. Ciência Florestal; v.14, n.2, p.157-168, 2004.

MELO, R. R. Dinâmica de ocorrência de incêndios florestais em unidade de conservação influenciada por diversos usos e cobertura do solo: APA Gama e Cabeça de Veado - DF. 2018. 85 f., il. Dissertação (Mestrado em Ciências Florestais) - Universidade de Brasília, Brasília, 2018

NADERPOUR, M. et al. Forest fire induced Natech risk assessment: A survey of geospatial technologies. Reliability Engineering and System Safety, v. 191, p. 106558, 2019.

OLIVEIRA, G. Q. DE et al. Desenvolvimento inicial de dois híbridos de eucalipto submetidos à irrigação. Eng. Agríc., v. 34, n. 6, p. 1099-1109, 2013.

OLIVEIRA, J. A. M. de. Balanço hídrico climatológico e classificação climática de Thornthwaite e Mather para o município de Conceição do Mato Dentro - MG. Revista Brasileira de Agricultura Irrigada, v. 13, n. 1, p. 3203 3211, 2019.

RAMALHO, A. H. C. et al. Geotechnology applied to predict the risk of occurrence of fire in the Atlantic Forest. Revista Ibero-Americana de Ciências Ambientais, v. 12, n. 1, p. 707-720, 2021.

RIBEIRO, L. et al. Zoneamento De Riscos De Incêndios Florestais Para a Fazenda Experimental Do Canguiri, Pinhais (Pr). Floresta, v. 38, n. 3, p. 561-572, 2008.

RIBEIRO, J. F.; WALTER, T. M. B. As principais fitofisionomias do bioma Cerrado. In: SANO, S. M.; ALMEIDA, S. P.DE. RIBEIRO, J. F. (Ed.). Cerrado: Ecologia e Flora. Brasília: EMBRAPA Informações Tecnológica; Planaltina: Embrapa Cerrados, p. 152- 212, 2008.
RODRÍGUEZ, M. P. R. et al. Comparação entre o perfil dos incêndios florestais de monte alegre, Brasil, e de pinar Del Rio, Cuba. Floresta, v. 43, n. 2, p. 231- 240, 2013.

SOARES, R. V.; BATISTA, A. C. Incêndios florestais: controle, efeitos e uso do fogo. Curitiba: Universidade Federal do Paraná, 2007.

SOARES NETO, G. B. et al. Riscos de incêndios florestais no parque nacional de Brasília - Brasil. Territorium, v. 23, p. 161-170, 2016.

SMA. Operação Corta Fogo. Disponível em: $<$ https://www.infraestruturameioambiente.sp.gov.br/corta fogo/>. Acesso em: 16 jul. 2021.

TEBALDI, A. L. C.; FIEDLER, N. C.; JUVANHOL, R. S.; DIAS, H. M. Ações de prevenção e combate aos incêndios florestais nas unidades de conservação estaduais do Espírito Santo. Floresta e Ambiente, Rio de Janeiro, v. 20, n. 3, p. 538-549, 2013.

VELOSO, H. P, RANGEL F.A.L. R; LIMA, J. C.A. Classificação da vegetação brasileira, adaptada a um sistema universal. Rio de Janeiro IBGE,DERMA, 123 p, 2012.

WORLDCLIM. Série histórica de precipitação (1981 2021), Disponível em: <https://www.worldclim.org/data/index.html>. Acesso em: 15 jul. 2021. 